\title{
AS ESCOLAS RURAIS E A ORGANIZAÇÃO DO ENSINO PRIMÁRIO EM CIANORTE-PR (1950-1990)
}

\author{
Rosangela de Lima ${ }^{1}$ \\ Analete Regina Schelbauer ${ }^{2}$ \\ Universidade Estadual de Maringá - UEM
}

\section{RESUMO}

$\mathrm{O}$ artigo apresenta resultados parciais da pesquisa que objetivou investigar a história do ensino primário rural do Município de Cianorte-PR, entre as décadas de 1950 e 1990 . A existência de um acervo documental expressivo, porém disperso, apontou a necessidade de intervenção nos arquivos, consubstanciando um inventário de fontes, que, além de subsidiar esta e outras pesquisas, contribui para a preservação do patrimônio histórico escolar da comunidade em questão. Neste, abordamos os principais aspectos sobre os espaços escolares e a organização do ensino das escolas primárias rurais de Cianorte. Como resultado, considera-se que estas instituições foram construídas sob os princípios da simplicidade e do barateamento, minimizando os custos. A ausência de novos prédios escolares e a necessidade de ampliar as vagas apontaram caminhos para o atendimento da população rural a fim de democratizar o acesso ao ensino primário.

Palavras-chave: Educação Rural; Ensino Primário Rural em Cianorte-PR; Organização do Ensino.

\section{THE RURAL SCHOOLS AND THE ORGANIZATION OF RURAL PRIMARY TEACHING IN CIANORTE-PR (1950-1990)}

\begin{abstract}
The article presents partial outcomes of the research, which aimed to investigate the history of rural primary education in the municipality of Cianorte, state of Parana, from the 1950s to the 1990s. The existence of a significant documental archive, although scattered, pointed to the need of intervention in the files, constituting an inventory of sources, which offers support for this and other studies, besides contributing to preserve the school historical heritage of the community in question. This study, in particular, approaches the main aspects of school spaces and the organization of teaching in the rural primary schools of Cianorte. As a result, we take into consideration that these institutions were built upon the principles of simplicity and price reduction, thus minimizing costs. The lack of new school buildings and the need to raise vacancies showed ways of attending the rural population towards democratization of the access to primary teaching.

Key words: Rural Education; Rural Primary Teaching in Cianorte-PR; Organization of Teaching.
\end{abstract}

\section{Introdução}

No Brasil, iniciativas de pesquisadores têm voltado a atenção para o processo educacional brasileiro, valendo-se de investigações sobre a institucionalização da escola primária, abordando aspectos acerca da formação de professores, da cultura escolar, das reformas educacionais, da expansão das instituições escolares, entre outros. Sempre com a 
preocupação de conhecer as práticas e as formas de apropriações que ocorreram no interior da escola.

Entre os resultados de pesquisas na área, destacam-se Cultura material escolar: a escola e seus artefatos (MA, SP, PR, SC e RS, 1870-1925), organizada por Castro (2011); Escola primária na primeira república (1889-1930): subsídios para uma história comparada, organizada por Araújo, Souza e Nunes Pinto (2012); Reformas educacionais: as manifestações da Escola Nova no Brasil (1920 a 1946), organizada por Miguel, Vidal e Araújo (2011); Grupos Escolares: cultura escolar primária e escolarização da infância no Brasil (1893-1971), organizada por Vidal (2006); Alicerces da pátria: história da escola primária no Estado de São Paulo (1890-1976), de Souza (2009); Educação Rural em perspectiva internacional: instituições, práticas e formação de professores, organizada por Werle (2007). Produções como estas organizam os resultados de pesquisas e evidenciam ausência de informações na historiografia da educação brasileira, dentre elas, a questão da educação rural.

A educação rural no Brasil é um tema ainda não explorado suficientemente. $\mathrm{O}$ recente Dossiê Representações, práticas e políticas de escolarização da infância na zona rural, organizado por Souza e Ávila (2014), assim como o livro Educação Rural em perspectiva internacional: instituições, práticas e formação de professores, organizado por Werle (2007), e o artigo Estudos sobre educação rural no Brasil: estado da arte e perspectivas, de Damasceno e Beserra (2004), afirmam a necessidade de investimento em pesquisas regionais sobre o assunto. Quanto à preocupação com a educação rural no campo das pesquisas, Ávila (2013, p. 175) conclui que “[...] essa modalidade de ensino não tem assegurado o seu lugar na história da educação brasileira, assumindo, na melhor das hipóteses, um lugar secundário nas pesquisas historiográficas".

Neste sentido, concorda-se com Schelbauer (2014) quando afirma que a historiografia da educação paranaense carece de investigações que aprofundem a pesquisa no âmbito da escolarização primária no meio rural. Seguindo nesta direção, investigamos esta modalidade de ensino, a qual esteve presente no Município de Cianorte, entre as décadas de 1950 e 1990, situado ao norte do Estado do Paraná.

Com relação a este Estado, ao analisar os relatórios e mensagens de governo, a autora aponta a existência de 120 escolas primárias rurais subvencionadas pelo governo federal na década de 1920 e 254 na década seguinte. Ressalta, ainda, a presença de 1.288 escolas isoladas na década de 1930, sendo este o modelo de escola que predominou em relação à oferta do ensino primário no Estado, as quais se encontravam nas regiões mais afastadas dos centros urbanos e em áreas rurais.

Após a intensificação do movimento de colonização e de povoamento do interior do Estado, as escolas primárias rurais passaram a ser disseminadas no norte do Paraná (BAREIRO, 2007). Mas como esse processo ocorreu no Município de Cianorte? De que forma foi implementada a organização do ensino nestas escolas? Como se configuraram os espaços escolares rurais neste contexto?

Assim, a pesquisa objetivou investigar a história do ensino primário rural em Cianorte entre as décadas de 1950 e 1990, cujo período marca a inauguração do Patrimônio de Cianorte, em 26 de julho de 1953, sendo elevado a município em 13 de julho de 1955. É também na década de 1950 que aparecem os registros das primeiras escolas rurais, no ano de 1956. O recorte investigativo encerra-se na década de 1990, justificado pelo fato de que é nesta década que as escolas rurais deste município passaram pelo processo de nucleação ${ }^{3}$, sendo extintas no ano de 1999 (LIMA, 2015).

Mas por que Cianorte? Entre as questões que envolveram a localização espacial que delimitou a pesquisa, justificamos nossa escolha tanto pela ausência de conhecimentos 
sistematizados no campo da historiografia da educação rural em Cianorte-PR, assim como pelo volume de fontes documentais que se encontram preservadas no município. Além disso, convém ressaltar a importância dessas fontes documentais, sendo um patrimônio histórico escolar tanto para a comunidade local como para a comunidade científica, tendo em vista a possibilidade de inúmeras investigações com os acervos existentes. Durante a pesquisa, os documentos foram catalogados e organizados com o objetivo de sistematizar um instrumento de pesquisa, consubstanciando um inventário de fontes.

A diversidade de documentos textuais e iconográficos nos conduziu à abordagem fundamentada na Nova História Cultural, tendo em vista as muitas possibilidades de leitura das fontes disponíveis. A perspectiva de análise construída com base nesta concepção permite considerar que este trabalho se consubstancia em uma representação da história do ensino primário rural neste município, tratada como resultado de uma pesquisa histórica em tempo e espaço determinados, sendo possíveis outras leituras do objeto em questão. Segundo Chartier (1990, p. 59),

[...] essa historicidade exige em primeiro lugar que o "consumo" cultural ou intelectual seja ele próprio tomado como uma produção, que evidentemente não fabrica nenhum objecto, mas constitui representações que nunca são idênticas às que o produtor, o autor ou o artista, investiram na sua obra.

Neste sentido, considerando que a apropriação do conteúdo dos documentos é singular ao historiador que os analisa (CHARTIER, 1990), a presente produção é uma das leituras possíveis sobre esta modalidade de ensino em Cianorte.

Como procedimentos metodológicos, adotamos a pesquisa bibliográfica e documental, visto que, embora os acervos sobre o objeto de estudo sejam volumosos, entendemos que a história não se faz com mera descrição de dados. "No atravessamento dos documentos, perceber as recorrências, os indícios como formas de pensar a educação e as múltiplas relações sócio-político-econômicas, que produzem os discursos" (LUCHESE, 2014, p.151) são tarefas fundamentais no exercício da pesquisa. Para tanto, há que se estabelecer as devidas relações com as produções historiográficas existentes.

Igualmente importante é analisar as normas e finalidades que regem a escola, presentes nos documentos oficiais, os quais se tem acesso mais facilmente, no entanto, como insistiu Julia (2001, p. 19): “[...] os textos normativos devem sempre nos reenviar às práticas; mais que nos tempos de calmaria, é nos tempos de crise e de conflitos que podemos captar melhor o funcionamento real das finalidades atribuídas à escola".

Nesta perspectiva, o artigo apresenta a contextualização do tema, com o objetivo de situar as instituições escolares estudadas no contexto de Cianorte e do Paraná, onde os documentos foram produzidos, veiculados e apropriados. Como explicita Magalhães (2004, p. 134): "A relação entre as instituições educativas e a comunidade envolvente estrutura-se numa abordagem cruzada dos planos macro, meso ou micro-histórico [...]". Por conseguinte, dar-se-á atenção às instituições, abordando os principais aspectos sobre os espaços escolares e a organização do ensino primário rural neste município.

\section{A escola rural no contexto de Cianorte}

O processo de colonização do território localizado ao norte do Estado do Paraná iniciou-se por volta da década de 1920, por meio de concessões a companhias de colonização (STECA; FLORES, 2002). A possibilidade de concretização desse processo, segundo Kohlhepp (2014), teve início pouco tempo depois da Proclamação da República, 
em 1889. Foram concedidas à Companhia Estrada de Ferro São Paulo-Rio Grande milhares de quilômetros quadrados de terras para que o espaço que compreende o noroeste e oeste do Estado do Paraná fosse colonizado. Porém, o não cumprimento dos termos da concessão pela companhia ferroviária fez com que, anos depois, as terras fossem devolvidas ao Estado.

Nesse sentido, a "[...] Revolução de 1930 trouxe a revogação de várias concessões de terras que não tinham preenchido as condições legais dentro de prazo de 5 anos" (KOHLHEPP, 2014, p. 54). Além disso, o autor afirma que a colonização agrária do norte do Paraná foi dificultada pela presença de dois grupos distintos na região: "os intrusos", que ocupavam as terras e delas saíam mediante uma "compensação financeira", e os "posseiros", cujas famílias cultivavam as terras desocupadas e tinham interesse de obter sua posse.

Após o início da década de 1930, em que as crises cafeeira e econômica mundiais atingiram o grau mais elevado no período, a colonização do Norte Novo do Paraná iniciou seu processo por intermédio do planejamento colonizador da Companhia de Terras Norte do Paraná - CTNP, em parceria com a Paraná Plantations Ltd. Tais empresas eram de origem inglesa e privadas, fundadas por Lord Lovat, um escocês especialista em áreas como a agricultura, o reflorestamento e a colonização (KOHLHEPP, 2014).

A sede da CTNP era em São Paulo e tinha como objetivos realizar operações de compra e exploração de terras, além de conseguir pessoas que se interessassem em colonizá-las. A Paraná Plantations, por sua vez, com sede em Londres, financiava o grande projeto de colonização. A aquisição das terras do norte paranaense pela CTNP contou com o apoio do governador do Estado na época, Senhor Munhoz da Rocha, e foi efetivada mediante a compra de todos os títulos de terras legais ou falsificados e por compensações financeiras realizadas a posseiros ou intrusos, por preços muito baixos (KOHLHEPP, 2014).

Em 1944, por ocasião da II Guerra Mundial, a CTNP foi vendida a um grupo de brasileiros, entre eles funcionários da própria companhia e banqueiros de São Paulo e Rio de Janeiro. No mesmo ano, a área denominada gleba Cruzeiro, situada no norte novíssimo, foi adquirida pela Companhia. Em 1951, a empresa recebeu o nome de Companhia Melhoramentos Norte do Paraná - CMNP (KOHLHEPP, 2014; SOUZA, 2010).

Na década de 1950, a colonização avançou em direção às terras do noroeste. Em 26 de julho de 1953, o Patrimônio de Cianorte foi fundado pela CMNP, cujo nome homenageia a empresa. Cianorte foi elevada a município em 13 de julho de 1955. Assim como muitos municípios da região, fez parte de um processo de colonização sistematicamente planejado pela CMNP (COMPANHIA MELHORAMENTOS NORTE DO PARANÁ, 1975).

Muitas disputas envolveram a questão da posse de terras no Estado do Paraná. A ausência de uma política confiável de compra e venda de terras pela ação colonizadora estatal, bem como os diversos problemas com relação ao transporte e acesso às áreas urbanas, no âmbito público, diferenciavam o planejamento de colonização e povoamento das áreas pertencentes à CTNP e, mais tarde, à CMNP (KOHLHEPP, 2014).

A historiografia tem apresentado questionamentos acerca desses processos de colonização ${ }^{4}$, demonstrando que não foram pacíficos, muito menos ideais, entretanto as condições com relação à prestação de serviços oferecidas pela CTNP aos colonos implementaram um projeto que favoreceu uma colonização mais intensiva no norte do Estado em meados do século XX. Segundo Kohlhepp (2014), entre os serviços prestados pela CTNP, estavam o fornecimento de meios de transporte, subsídios para o desmatamento, cuidados médicos, construção e manutenção de escolas. 
No período, a escolarização primária se constituía um desafio a ser vencido no Estado do Paraná. O número de instituições primárias não atendia à demanda de crianças em idade escolar. O governador Moisés Lupion relatou a preocupação do Estado:

No que se refere ao ensino primário, é sabido de todos o nosso profundo déficit em unidades escolares, em todo Estado. Evidentemente, tal déficit não pode ser sanado no primeiro instante e as medidas adotadas para enfrentá-lo tinham de ser medidas de emergência. Com essa preocupação, determinamos que, na abertura das aulas das escolas daquele grau, se procurasse recolher em nossos grupos e escolas isoladas existentes tôdas as crianças que batessem às suas portas. [...] Parece-nos que é mais justo dar um pouco a todos, do que recusar a muitos e muitos o que se dá a alguns (PARANÁ, 1956, p. 12).

A presente citação faz parte da Mensagem de Governo do Estado do Paraná, Senhor Moysés Lupion, por ocasião da abertura da Sessão Legislativa Ordinária no ano de 1956. Ela nos permite interpretar, inicialmente, o contexto da educação no Estado do Paraná na década de 1950, especialmente nos anos de 1955 e 1956, momento em que Cianorte apontava como um núcleo em desenvolvimento, com sua elevação a município em 1955.

Segundo a mensagem, as escolas isoladas deveriam atender a todas as crianças, cujas famílias procurassem por escolarização. Possivelmente, a medida tomada pelo governo sobrecarregou as escolas que, por sua vez, não tinham os recursos necessários à sua manutenção. No caso de Cianorte, as escolas isoladas estavam por ser construídas.

O Paraná viveu um intenso processo de colonização e povoamento de suas terras em meados do século XX. Com relação ao período de 1930 a 1960, Schelbauer (2014) afirma que os governos do Estado ${ }^{5}$ foram " [...] caracterizados por práticas administrativas voltadas ao povoamento do território, por meio dos trabalhos de colonização das regiões Norte, Oeste e Sudoeste do Estado [...]" (p. 77). Nesse sentido, os esforços para desenvolver e modernizar o Estado, no período, transitavam entre a agricultura, o transporte para o escoamento da produção e a educação do povo.

Tendo em vista a ocupação do interior do território paranaense e o baixo custo, as escolas isoladas se disseminaram, sustentando a expansão da escolarização primária. Assim, a escola rural teve papel relevante no movimento de colonização do Estado do Paraná, uma vez que as famílias concentravam-se na zona rural e lutavam pela educação de seus filhos.

A colonização do Norte e Sudoeste do Estado ocorreu com a ocupação da área rural pelas frentes pioneiras o que contribuiu para a predominância da população rural sobre a urbana no Estado do Paraná. À medida que ocorria a fixação das comunidades rurais também eram implantadas as escolas para essas comunidades fruto da iniciativa destas (BAREIRO, 2007, p. 98).

Quanto às modalidades de escolas rurais existentes no Paraná, Schelbauer (2014) descreve os tipos de denominações e modelos que favoreceram o acesso à educação no meio rural entre as décadas de 1930 e 1960, paralelamente às escolas urbanas. São "[...] as escolas de trabalhadores rurais e de pescadores, [...]; o grupo escolar rural e a escola primária rural, modelo de escola isolada que atendia às populações rurais, também denominadas nos documentos como Casa Escolar Rural” (p. 80). 
Em Cianorte, as escolas rurais que permaneceram em funcionamento entre as décadas de 1950 e 1990, denominadas Escola Isolada, Escola Rural, Escola Rural Municipal, Escola Municipal ou apenas Escola, se ajustam ao modelo de escola isolada informado pela autora, com estrutura simples e edificada no meio rural, tendo como organização classe multisseriada e unidocente.

As três primeiras escolas rurais no município foram construídas no ano de 1956. Gradativamente, esse número aumentou de acordo com o crescimento da população rural. Nos anos seguintes, foram construídas mais oito escolas rurais chegando a onze na década de 1950. Na década de 1960 totalizaram-se 48 instituições e, na década de 1970, somaramse mais três escolas, contabilizando-se 62 unidades na extensão rural de Cianorte (LIMA, 2015).

Assim como em outros municípios do Estado, inicialmente, a população habitava, em maior número, a zona rural. Este quadro teve suas modificações ao longo dos anos que recortam a pesquisa, demonstrando a mobilidade do campo para a cidade. Entre as décadas de 1960 a 2000, dados do censo demográfico, obtidos pelo Instituto Brasileiro de Geografia e Estatística - IBGE, demonstram o progressivo aumento da população urbana e o consequente decréscimo da população rural. A tabela a seguir demonstra esta afirmativa:

Tabela 1 - Evolução da população urbana e rural de Cianorte.

\begin{tabular}{cccccc}
\hline Localização & \multicolumn{5}{c}{ Ano } \\
\hline & $\mathbf{1 9 6 0}$ & $\mathbf{1 9 7 0}$ & $\mathbf{1 9 8 0}$ & $\mathbf{1 9 9 1}$ & $\mathbf{2 0 0 0}$ \\
Urbana & $\ldots$ & 23.936 & 29.406 & 37.852 & 49.637 \\
Rural & $\ldots$ & 29.089 & 20.232 & 11.997 & 7.753 \\
Total & 31.987 & 53.025 & 49.638 & 49.849 & 57.390 \\
\hline
\end{tabular}

Fonte: Dados de Censos Demográficos organizados pelas autoras (IBGE,1960, 1970, 1980, 1991, 2000, 2010).

Além da movimentação evidenciada por meio da tabela 1, observa-se que o número populacional total teve uma queda entre as décadas de 1970 e 1980, obtendo pequeno aumento em 1991. A partir desta década, o número total de residentes em Cianorte aumentou consideravelmente, mas o número de moradores da zona rural continuou a diminuir.

Vale ressaltar que, em 1969, ocorreu uma forte geada que causou sérios prejuízos na colheita do café em 1970, e acelerou-se a migração de parte da população rural para a zona urbana no norte do Estado do Paraná (KOHLHEPP, 2014). De acordo com Capelo (2000), o baixo preço do café, o aumento da produção internacional e as exigências do mercado somados à inserção da legislação trabalhista no meio rural e a consequente mudança para a forma de trabalho assalariado contribuíram para a policultura e para a desocupação progressiva do campo desde meados da década de 1960, evidenciando a queda da cafeicultura.

Com a desocupação do espaço rural de Cianorte em grande escala, os investimentos em educação tomaram rumos diferenciados na política do município, diante da suposta ausência de necessidade de manter escolas no campo. Os índices da inversão na estatística entre as zonas rural e urbana, com início em 1970, apontavam que 45,14\% da população residiam na zona urbana e 54,86\% na zona rural. Dez anos depois, no ano de 1980, 
registrava-se o percentual de 59,24\% de residentes na zona urbana contra 40,76\% na zona rural (IBGE, 1970; 1980 respectivamente).

Mesmo diante desse contexto, as escolas rurais multisseriadas e unidocentes permaneceram em funcionamento, em Cianorte, por quase quarenta anos. Sua reorganização, na década de 1990, promoveu mudanças na estrutura para o atendimento das crianças na zona rural até o ano de 1999 (LIMA, 2015).

Conforme Lima (2015), o ano de 1956 marca o início da Era das escolas rurais no Município de Cianorte. Com relação à extinção destas escolas, o ano de 1998 é identificado como último em que as escolas tiveram seus prédios localizados na zona rural, atendendo a esta população, uma vez que os processos de nucleação das escolas rurais se efetivaram durante a década de 1990, concentrando professores e alunos em seis unidades escolares. Em 1999, a última unidade escolar rural sofreu alterações quanto à sua localização, passando a funcionar na zona urbana. A tentativa era de que a nucleação favorecesse o fim de classes multisseriadas, consideradas "contraproducentes" por seus idealizadores no município (CIANORTE, 1997).

Muitas escolas rurais do Estado do Paraná passaram pelo processo de nucleação, semelhante à consolidação das escolas rurais, que consistia em concentrar professores e alunos de pequenas unidades escolares dispersas na zona rural em um prédio maior e com melhor estrutura para o ensino, minimizando os custos. Isto era possível mediante a utilização do transporte escolar e favorecia a organização de classes unisseriadas (CAPELO, 2000; BAREIRO, 2007; TIBUCHESKI, 2011). Esclarece Ramos (1991) que, além desses objetivos, as escolas rurais consolidadas visavam ampliar o atendimento para oito anos, fato que não ocorreu em Cianorte.

Com o processo de nucleação se efetivando, muitos recursos foram direcionados às seis escolas-núcleo de Cianorte, com reformas, ampliações e aquisição de materiais e equipamentos, além dos esforços empreendidos na tentativa de convencer as famílias a enviarem seus filhos às escolas nucleadas, que, muitas vezes, ficavam distantes dos sítios e fazendas onde residiam. Além disso, as condições do transporte escolar eram precárias e as poucas unidades disponíveis ficavam superlotadas.

Entretanto, a nucleação não garantiu a permanência dessas escolas na zona rural de Cianorte, sendo cessadas as atividades de cinco instituições no final do ano letivo de 1998. Em 1999, os alunos foram transferidos para uma delas, sob a argumentação da Secretaria Municipal de Educação de que o número de alunos havia reduzido consideravelmente. No mesmo ano, a escola foi transferida para a zona urbana, alterando-se sua denominação e domicílio no ano de 2000, deixando de ser reconhecida como escola rural. Com a concentração de alunos e professores em uma unidade escolar na zona urbana e a utilização de recursos federais, as condições do transporte melhoraram, acalmando, pelo menos em parte, as famílias.

Observa-se que nem todas as escolas rurais foram extintas oficialmente. Das 62 unidades que funcionaram na década de 1970, muitas foram sendo desativadas, restando nove escolas após o processo de nucleação, na década de 1990, sendo seis escolas nucleadas e três que sofreram alterações quanto à sua denominação, permanecendo em atividade, na zona urbana, até os dias atuais.

\section{Os espaços escolares e os materiais disponíveis para o ensino primário rural}

No século XX, o maior número de matrículas e os melhores edifícios escolares se concentravam na zona urbana, estabelecendo a diferença entre escolas urbanas e rurais (FARIA FILHO; VIDAL, 2000). Em conformidade com os autores, as escolas das zonas 
rurais eram construídas sob os princípios da simplicidade e do barateamento, sem padrões definidos, e deveriam atender às condições mínimas, como salas de aula, pátio coberto, sanitários e residência do professor.

Foi nas décadas de 1950 e 1960 que este modelo de escola mais barato e funcional se disseminou no Brasil (FARIA FILHO; VIDAL, 2000). Nesse período, não foi diferente no Estado do Paraná, uma vez que as frentes pioneiras de colonização e povoamento tomavam iniciativas para a construção de escolas (BAREIRO, 2007).

Em 1962, um convênio entre os governos federal e estadual, referente ao Programa Educacional de Emergência, foi firmado no Paraná. Entre os objetivos para reduzir os problemas educacionais do Estado, estavam a "[...] construção, equipamento e recuperação de escolas urbanas e rurais, visando ampliar prontamente a rede escolar primária e média do País" (PARANÁ, 1962, p. 7).

Mas a situação dos municípios recentemente criados no norte do Paraná, em meados do século XX, ainda carecia de infraestruturas básicas, como melhoria no transporte, comunicação, educação, saúde e saneamento. O planejamento de colonização, organizado pela CTNP, denominado "Colonização-Dirigida"6, promoveu um intenso processo de ocupação e povoamento, porém não extraiu tais dificuldades.

Com relação ao setor educacional, no Município de Cianorte, a CMNP incentivou a ocupação do território e algumas vezes viabilizou a construção de escolas com o fornecimento da madeira, fruto da derrubada da floresta no próprio local. Os terrenos em que as escolas rurais foram construídas eram, por vezes, cedidos por proprietários de terras. Esta situação é corroborada por Faria Filho e Vidal (2000) ao relatarem que, já na década de 1930, os discursos e projetos sobre a construção de escolas manifestavam-se a favor de que ela fosse "[...] funcional, racional, com uso de materiais da região e atendendo às condições de clima, usos e costumes" (p. 29).

No município, as escolas primárias rurais foram construídas entre as décadas de 1950 e 1970. A maioria foi feita com madeira e telhas de barro; algumas com vidraças e outras com janelas de madeira. Apresentavam características semelhantes e diferentes entre si no que diz respeito ao espaço físico, possuíam uma ou mais salas de aula e outros espaços como cozinha, mictório e casa do professor, não havia pátio coberto para recreio e nem banheiros. Em apenas duas escolas aparecem registros de existência de três sanitários, dois destinados ao uso pelos alunos e um para o professor (LIMA, 2015).

A questão do saneamento não era uma realidade próxima. As estruturas simplificadas da maioria dos prédios escolares de Cianorte não contemplavam instalações adequadas. Era comum, naquele momento, a construção de mictórios ${ }^{7}$, já que a maioria das escolas rurais, assim como as residências localizadas na zona rural e em periferias urbanas, não possuíam banheiros com as devidas instalações sanitárias.

As edificações refletiam, em grande parte, a proposta de escola rural simplificada, tal como relatam Faria Filho e Vidal (2000). A distribuição dessas construções era feita de acordo com os locais em que havia maior número de residentes. O mapa a seguir apresenta a localização das escolas rurais no território de Cianorte. 
Mapa 1 - Localização das escolas rurais no Município de Cianorte.

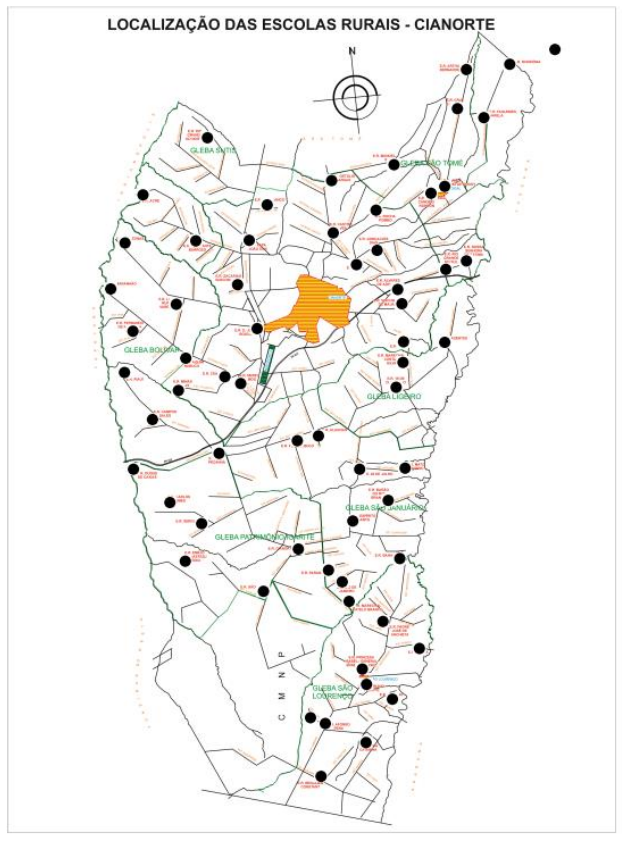

Fonte: LIMA, 2015.

De 1956 até o final desta década, onze escolas foram construídas. Durante a década de 1960, ocorreu a proliferação de instituições primárias na zona rural, chegando a 48 unidades, marcando a expansão dessa modalidade de ensino no município. A partir de 1970, mais três escolas se estabeleceram, formando o conjunto de 62 escolas rurais na região. Estas escolas, muitas vezes construídas pela iniciativa da população e com subsídios da companhia colonizadora, contaram com a subvenção em grande parte da esfera municipal.

No que se refere a outros espaços, apenas uma escola rural $^{8}$ possuía uma biblioteca, um almoxarifado e uma secretaria, além de três salas de aula e dois sanitários, cujo prédio escolar, situado no Patrimônio de São Lourenço, atualmente distrito de Cianorte, diferenciava dos demais pela sua estrutura mais moderna e de alvenaria, assemelhando-se a um grupo escolar.

Quanto às demais escolas rurais, não havia um padrão estabelecido para suas construções, exceto com relação ao espaço das salas de aula. Todas as escolas contavam com, no mínimo, duas dependências, e possuíam salas de aula com 48 metros quadrados. A cozinha, nem sempre presente, tinha entre 9 e 22 metros quadrados; 21 instituições possuíam residência anexa destinada ao professor, correspondendo a $36 \%$ das escolas rurais.

A presença da casa do professor pode estar relacionada à intenção de fixar estes profissionais nas localidades onde atuavam, como incentivo e complementação dos salários. Dados do livro memorialista sobre a história do município informam que as residências foram construídas para que o professor não faltasse às aulas em dias chuvosos, uma vez que a chuva impossibilitava a locomoção por conta das péssimas condições das estradas (Cioffi et al. 1995).

No entanto, essa informação pode demonstrar o estranhamento em face da política e dos discursos voltados para a educação rural na época, que objetivavam educar a comunidade local mediante uma ação civilizatória. Esta ação deveria disseminar novos valores e atitudes, consubstanciando mudanças no comportamento da população rural em 
relação à valorização do trabalho, do asseio e hábitos saudáveis, integrando-a aos princípios da economia e da sociedade modernas, atreladas ao desenvolvimento capitalista pelo qual o Brasil ansiava no período democrático, de 1946 a 1964 (ANDRADE, 2014).

As dependências presentes nas construções escolares rurais do município assemelham-se aos projetos formativos instaurados no Brasil de 1946 a 1964, conforme aponta o autor ao destacar o vínculo da construção simbólica da ordem social à construção material dos prédios escolares. A própria residência da professora, de estrutura simples, mas superior à dos moradores locais, serviria como visão de uma possibilidade ao alcance de todos. Não por acaso, a casa da professora estaria ali estruturada na zona rural, servindo como exemplo a ser seguido pelas pessoas da comunidade.

Quanto mais escolas, maior seria a influência na população rural. Em Cianorte, construída em locais onde havia demanda por escolarização, uma sala de aula serviria ao propósito de ensinar a ler, escrever e contar. Porém, era comum muitas crianças matriculadas nas turmas, mas o elevado número de desistências e transferências esvaziava as salas de aula.

O número de classes disponíveis foram aspectos relevantes para a organização do ensino primário rural neste município. Quase $65 \%$ das escolas rurais possuíam apenas uma sala de aula e cerca de $25 \%$ possuíam duas. Entre os $10 \%$ restantes estão os dados de escolas com três e seis salas e as que não puderam ser analisadas.

Neste ambiente, a mobília e materiais para o ensino se resumiam a carteiras duplas e simples, mesas e quadros de giz. A presença de dois tipos de carteiras escolares nas escolas rurais de Cianorte é um dado bastante interessante. Apesar das carteiras individuais fazerem parte da mobília dos primeiros grupos escolares da capital do Estado do Paraná, no início do século XX, às escolas rurais de Cianorte foram legadas as carteiras duplas em sua maioria, sendo gradativamente substituídas a partir de meados da década de 1970.

Com relação aos materiais de consumo, os documentos informam a presença de livro didático, cartilhas, cadernos e lápis. As orientações aos professores para que utilizassem papel de embrulho e recortes de jornais para o trabalho com as primeiras séries e as solicitações para que não pedissem muitos materiais aos alunos indicam a carência de recursos (CIANORTE, 1970-1989; 1977-1996).

Em 1975, a circular $n^{\circ}$ 03/75 da Inspetoria Regional de Ensino transcreveu a Resolução Estadual $n^{\circ}$ 296/75, para que os professores tomassem conhecimento de que seria proibido impedir o acesso dos alunos por falta de uniforme ou de materiais escolares. $\mathrm{O}$ documento ainda dizia que as escolas deveriam providenciar os materiais para as crianças carentes por meio da Contribuição Comunitária ou da "Associação de Pais e Professores" (CIANORTE, 1975).

A Associação de Pais e Mestres - APM e a caixa escolar destacam-se, em Cianorte, como instituições auxiliares da escola (SOUZA, 2013), as quais deram suporte ao funcionamento das escolas rurais, inclusive com relação ao auxílio às crianças que necessitavam de materiais, roupas, alimentação, medicamentos, entre outros. As ações da APM contribuíam para angariar recursos para a caixa escolar e para a organização e asseio das instituições, por meio de mutirões de limpeza, horta escolar, campanhas para arrecadar fundos, agasalhos, rifas, festas, etc. Por sua vez, a caixa escolar era um tema bastante comentado em meio aos assuntos educacionais e os professores, em cada reunião de pais, apresentavam os gastos, os saldos e os resultados de campanhas realizadas para complementar a renda da escola.

Pelo exposto sobre as estruturas disponíveis para o ensino e a cultura material das escolas primárias rurais de Cianorte, consideramos que a afirmação de Souza (2013) acerca da escassez de objetos de ensino nas escolas primárias do Brasil, no século XX, 
acompanha nossas reflexões. A ausência de recursos e as precárias condições de trabalho, em Cianorte, ancoraram a aprendizagem das crianças na segurança que as cartilhas e o quadro negro podiam oferecer.

\section{As escolas primárias rurais e a organização do ensino}

As escolas rurais de Cianorte foram gradativamente criadas a partir do ano de 1956. Porém os primeiros documentos referentes a elas datam de 1962, por ocasião de registros, em Livros Ata (CIANORTE, 1962-1979), dos rituais de exames finais, que eram feitos com a presença de uma comissão examinadora. Não por acaso, esses documentos existem:

Art. 16. É da competência dos Estados e do Distrito Federal autorizar o funcionamento dos estabelecimentos de ensino primário e médio não pertencentes à União, bem como reconhecê-los e inspecioná-los.

$\S 1^{\circ}$ São condições para o reconhecimento:

[...]

c) escrituração escolar e arquivo que assegurem a verificação da identidade de cada aluno, e da regularidade e autenticidade de sua vida escolar (BRASIL, 1961).

A presença de uma Lei para regular as ações dos estabelecimentos educacionais criou a necessidade de efetuar registros que pudessem garantir a veracidade de seus atos e conseguir reconhecimento dos órgãos oficiais. A partir de 1962, as escolas rurais de Cianorte passaram a registrar os resultados de sua competência: a instrução primária.

Em consonância com a LDB 4024/61 e com os documentos sobre a organização da seriação e programas para os grupos e casas escolares e escolas isoladas do Estado do Paraná ${ }^{9}$, os registros identificam a organização seriada, de $1^{\mathrm{a}}$ a $4^{\mathrm{a}}$ séries, por intermédio dos exames finais. O documento $O$ Ensino Primário no Paraná instituído pelo Decreto $\mathrm{n}^{\circ}$ 10.290, de 13 de dezembro de 1962 ,

[...] deu nova estrutura ao ensino primário no Estado do Paraná, aumentando a sua duração, a partir do ano letivo de 1963, de 4 para 6 séries anuais nos grupos escolares, de 4 para 5 séries nas casas escolares e de 3 para 4 séries nas escolas isoladas (PARANÁ, 1963b, p. 3).

Nas escolas rurais de Cianorte, o ensino primário foi estabelecido em quatro séries, inserindo-as no modelo de escola isolada, expresso no documento supra citado. Pela indicação, o ensino primário em escolas isoladas era ministrado, anteriormente à Lei, em três séries. É evidente a diferenciação da oferta de ensino entre os tipos de escolas e a sua localização.

Em Cianorte, embora os registros apresentem a organização dos exames em cada série separadamente, os dados sobre os professores regentes indicam a existência de classes multisseriadas e unidocentes.

Após a primeira iniciativa de nucleação das escolas rurais de Cianorte em meados da década de 1980, as classes multisseriadas foram lentamente sendo substituídas pela organização seriada. As turmas seriadas foram organizadas, inicialmente, em escolas que possuíam duas ou mais salas de aula. Entretanto, essa organização dependia do número de alunos e da disponibilidade de professores, o que talvez tenha permitido a existência de turmas seriadas antes do processo de nucleação. 
Sobre a organização multisseriada, Cardoso (2013, p. 33) afirma: "A nomenclatura escolas multisseriadas aparece no cenário educacional após os anos de 1970. Antes, as escolas que mantinham, na mesma sala, várias séries sob a regência de um só professor eram denominadas escolas isoladas". Para a autora, entender o significado do termo "multisseriado" requer que seja retomado o sentido do que significa o seu oposto, ou seja, seriado ou "unisseriado". Sendo assim, o modelo de escola graduada pressupõe a divisão do ensino de maneira que os alunos sejam distribuídos em classes supostamente homogêneas com relação ao grau de adiantamento, como uma forma de classificação (SOUZA, 2009). Cada turma ou classe se refere a uma mesma série em curso. Logo, as turmas multisseriadas seguem um sistema diverso, formada por alunos em diferentes níveis de aprendizagem, porém sob a regência de um único professor.

Embora o modelo de escola graduada tenha se expandido no país durante o século XX, na primeira década do século XXI, o Brasil ainda contava com o ensino em turmas multisseriadas. Em 2011, havia cerca de 95.402 classes multisseriadas no ensino fundamental, sendo 4.585 na Região Sul e 699 no Estado do Paraná (CARDOSO, 2013). Em Cianorte, atualmente, não há turmas multisseriadas na rede pública. Elas foram gradativamente extintas durante a década de 1990, substituídas com a nucleação das escolas rurais.

No entanto, antes do processo de nucleação, as instituições analisadas possuíam a mesma organização em suas práticas: as classes multisseriadas e unidocentes. Mas a organização das turmas dependia do número de alunos, o que justifica a presença de uma $1^{\mathrm{a}}$ série em um turno e $2^{\mathrm{a}}, 3^{\mathrm{a}}$ e $4^{\mathrm{a}}$ em outro, na mesma escola. Em geral, os professores atendiam a duas séries ao mesmo tempo, mas isso não era uma regra, visto que havia classes multisseriadas com alunos de todas as séries.

Uma vez sentida a necessidade de ampliar o atendimento em vista do número expressivo de alunos e a ausência de novos prédios escolares, o desdobramento em três e até quatro turnos foi operacionalizado em algumas unidades escolares. Em sua maioria, os horários registrados indicam o período de quatro horas diárias de atendimento em sala de aula, o que não exclui outras formas de organização do tempo, entre 2 e 6 horas de aulas por dia. Tais horários, em relação ao início e término das aulas, diferenciavam-se de uma escola para outra, visando a conciliar a distância da escola e as condições de transporte para os professores que residiam na zona urbana ${ }^{10}$.

Os turnos foram uma saída de emergência para o problema da falta de vagas na zona rural de Cianorte, inclusive para a questão dos índices de analfabetismo que assolavam o estado e o país na segunda metade do século XX. Ante tal problema, as escolas rurais atendiam aos alunos de acordo com a disponibilidade de espaços e de acomodações. Para tanto, era preciso organizar o atendimento em até quatro turnos, denominados turno da manhã, do meio ou intermediário, da tarde e noturno, a maioria sem intervalo entre eles, coincidindo os horários de saída da primeira classe com a entrada da segunda quando atendidas pelo mesmo professor, o que era muito comum.

O número de alunos por escola apresenta grandes diferenças, sendo um determinante para sua organização. As escolas que contavam com um número inferior a trinta alunos realizavam atendimento em apenas um turno. As demais se organizavam de acordo com a demanda, o espaço existente e a disponibilidade dos professores, já que a maioria deles residia na zona urbana.

A presença de cursos primários no período noturno, na época, indica uma preocupação com a escolarização de jovens e adultos, porém o pequeno número de classes demonstra que o convencimento de participação nas aulas, aos que não foram alfabetizados em idade escolar, não era uma tarefa fácil, em especial com os habitantes da zona rural. A 
frequência escolar, tanto de crianças quanto de adultos da zona rural, era um problema identificado em nível nacional, devido ao trabalho nas lavouras (ÁVILA, 2013).

Com relação aos conteúdos escolares, antes de 1962, o ensino em escolas isoladas no Paraná deveria seguir as orientações dos "Programas Experimentais para escolas isoladas do Estado", dadas pelo Decreto Estadual n 9060 de 1953, cujo documento substituiu o "Programa para as escolas isoladas do Estado", estabelecido em 1949 (CAINELLI, 1994, p. 87).

Segundo o Programa, o curso primário estava organizado em três séries anuais, contemplando as seguintes disciplinas: $1^{\text {a }}$ série: Português; Linguagem Escrita; Caligrafia; Aritmética; Desenho; Geografia; História da Pátria; Educação Cívica, Moral e Social; Ciências Físicas e Naturais; Higiene; Trabalhos Manuais; Canto; Educação Cívica; 2a série: Português; Aritmética; Geometria; Educação Cívica, Moral e Social; Desenho; Geografia; História da Pátria; Ciências Físicas, Naturais e Agricultura; Instrumentos Agrícolas e o seu emprego; Higiene; Trabalhos Manuais; Canto; Educação Física; $3^{\text {a }}$ série: Português; Caligrafia; Aritmética; Geometria; Desenho; Geografia; História da Pátria; Educação Cívica, Moral e Social; Ciências Físicas, Naturais e Agricultura; Higiene; Trabalhos Manuais; Canto; Educação Física (CÉSAR, apud CAINELLI, 1994, p. 92-93).

A partir de 1963, com o documento que organizou a nova seriação e programas para as escolas isoladas do Estado do Paraná, instituído pelo Decreto $\mathrm{n}^{\mathbf{0}} 10.290$, de 13/12/1962, e aprovado pela Portaria 110/63, foram elencadas as disciplinas de Linguagem, Matemática, Estudos Sociais e Ciências Naturais e Higiene para as quatro séries iniciais (PARANÁ, 1963a).

Em Cianorte, as disciplinas ministradas compõem o quadro a seguir. A existência de três tipos de séries documentais permitiu a visualização das distintas formas de registros em determinados períodos:

Quadro 1 - Comparativo entre os documentos/disciplinas ministradas nas Escolas Primárias Rurais de Cianorte - 1962-1999.

\begin{tabular}{|c|c|c|c|}
\hline $\begin{array}{l}\text { Ano/ } \\
\text { Período }\end{array}$ & Livros Ata & Livros Registro $^{11}$ & Relatórios Finais \\
\hline 1962-1973 & - & - & - \\
\hline 1974-1977 & $\begin{array}{l}\text { Português, } \\
\text { Matemática e Estudos } \\
\text { Sociais. }\end{array}$ & - & - \\
\hline $1978-1979$ & $\begin{array}{l}\text { Comunicação } \\
\text { Expressão, Iniciação } \\
\text { às Ciências e Estudos } \\
\text { Sociais. } \\
\text { - }\end{array}$ & $\begin{array}{l}\text { Comunicação e Expressão, } \\
\text { Iniciação às Ciências e } \\
\text { Integração Social. }\end{array}$ & $\begin{array}{l}\text { Comunicação e Expressão, Estudos } \\
\text { Sociais, Ciências e Artigo } 7^{\circ} \\
\text { (Educação Moral e Cívica, } \\
\text { Educação Física, } \\
\text { Artística, Programa de Saúde e } \\
\text { Ensino Religioso }{ }^{12} \text { ). }\end{array}$ \\
\hline 1988 & - & 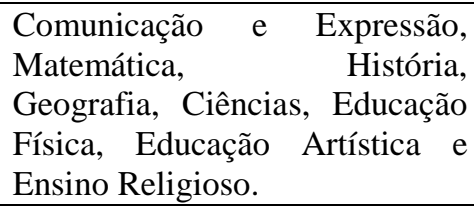 & $\begin{array}{l}\text { Português, Matemática, História, } \\
\text { Geografia, Iniciação às Ciências, } \\
\text { Ed. Física, Ed. Artística. }\end{array}$ \\
\hline $1989-1992$ & - & 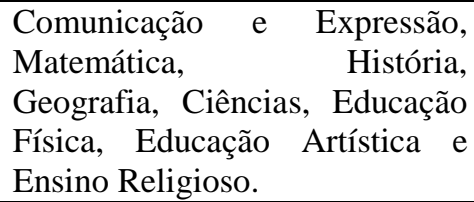 & $\begin{array}{l}\text { Português, Matemática, História, } \\
\text { Geografia, Iniciação às Ciências, } \\
\text { Ed. Física, Ed. Artística }^{13} \text {. }\end{array}$ \\
\hline
\end{tabular}




\begin{tabular}{|c|c|c|c|}
\hline 1993-1994 & - & - & Português, Matemática, História, \\
\hline $\begin{array}{l}1995- \\
1999^{15}\end{array}$ & - & $\begin{array}{l}\text { Português, Matemática, } \\
\text { História, Geografia, Iniciação às } \\
\text { Ciências. }\end{array}$ & $\begin{array}{l}\text { Geografia, Iniciação às Ciências, } \\
\text { Ed. Física, Ed. Artística }{ }^{14} \text {. }\end{array}$ \\
\hline
\end{tabular}

Fonte: LIMA (2015).

O quadro apresenta as disciplinas por ano ou período em que foram ministradas, demonstrando os documentos que contêm tais informações. Embora sejam perceptíveis as mudanças quanto às nomenclaturas de algumas disciplinas, os conteúdos elencados nos livros são praticamente os mesmos, indicando que há certa equivalência entre elas. Nesse sentido, Estudos Sociais, Integração Social e História e Geografia parecem equivalentes. Iniciação às Ciências abrange os conteúdos de Matemática e Ciências e Comunicação e Expressão equivale à disciplina de Português.

A questão das disciplinas escolares, no Estado do Paraná na década de 1980, é abordada por Rodrigues (2012). Em especial, discorre sobre os significados de um projeto de formação com base na mudança do "[...] componente conservador da Educação Moral e Cívica, incorporando nos programas de História uma perspectiva mais democrática, por meio de um discurso que pretendia trabalhar com conteúdos mais significativos à sociedade" (RODRIGUES, 2012, p. 87). Mas, como ela própria analisa, "[...] a seleção de conteúdo nas duas disciplinas prima pela manutenção da tradição do ensino nacionalista e patriótico" (p. 88).

Em meio às anotações dos conteúdos, especialmente com relação à disciplina de Integração Social ou equivalentes (Estudos Sociais; História e Geografia), observa-se a presença marcante de "Datas Comemorativas" ou "Datas Significativas" e recorremos novamente a Rodrigues (2012) quando pondera que, mesmo diante dos discursos que procuraram redirecionar os conteúdos de História, tendo em vista a substituição do regime ditatorial pelo democrático, o ideal de conformação dos sujeitos à nação se manteve na prática das salas de aula. Neste sentido, o civismo, trabalhado por meio dos personagens e datas cívicas, permaneceu na prática pedagógica das escolas rurais de Cianorte, conformando sua população a tais ideais.

Ante esta constatação, reafirmamos, juntamente com Rodrigues (2012), que a questão das mudanças nas nomenclaturas das disciplinas escolares ocorre de acordo com os discursos e concepções da época, assim como a forma como são ensinadas. Entretanto o seu conteúdo permanece imutável, resistindo "[...] a todas essas mutações, o que caracteriza as continuidades desse fazer" (p. 91). É o que se observa nas escolas primárias rurais de Cianorte, em consonância com o que observou a autora no Estado do Paraná.

Vale mencionar que as disciplinas registradas nas fontes históricas a partir de 1988 foram as contempladas no documento "Currículo Básico para a Escola Pública do Estado do Paraná" antes de sua publicação em 1990, apresentando divergência apenas com relação à nomenclatura de Língua Portuguesa, que aparece nos documentos como "Comunicação e Expressão", conforme os anos anteriores. A edição dos documentos Reorganização da escola pública de $1^{o}$ grau: proposta preliminar de trabalho (1987) e Projeto Pedagógico 1987-1990, organizados pelo Estado do Paraná, que se configuraram o norte da prática pedagógica no final da década de 1980 (PARRA, 2008), podem ter direcionado as mudanças ocorridas nos registros dos conteúdos na esfera municipal.

Outra influência estadual nas escolas rurais municipais diz respeito à organização do "ciclo básico"16 ocorrida nos anos de 1990 e 1992. O Ciclo Básico de Alfabetização CBA refere-se a um sistema que procurou ampliar o tempo de alfabetização das crianças no final da década de 1980 no Estado do Paraná e, dessa forma, diminuir os índices de repetência na $1^{a}$ série. Segundo o documento Currículo Básico para a Escola Pública do 
Estado do Paraná, o CBA foi implantado em 1988 e permitia "[...] o progresso sistemático do aluno no domínio do conhecimento, eliminando a reprovação na $1^{\mathrm{a}}$ série" (PARANÁ, 1990, p. 12). De acordo com este sistema, o aluno que não apresentasse rendimento escolar satisfatório seria encaminhado a outros serviços (PINESSO; MORI, 2008), o que pode explicar a existência de turmas de contraturno nos anos de 1990, 1991 e 1992.

Neste aspecto, a política de educação estadual atingiu parcialmente as unidades escolares rurais de Cianorte, consubstanciando duas novas situações: apenas em cinco escolas os alunos foram atendidos segundo as orientações do CBA; nas demais, a prática de retenção na $1^{\mathrm{a}}$ série continuou ocorrendo.

Nas escolas em que o CBA foi implantado, as crianças não mais ficaram retidas na $1^{a}$ série e foram ofertadas atividades de reforço àquelas que apresentaram dificuldades durante as aulas, no período contrário aos seus estudos, independente da série em que se encontravam. Essas ações indicavam certa preocupação com o ensino, mas a não aprendizagem dos alunos também eram resultantes, em parte, da formação precária de um percentual razoável de professores, pois as escolas rurais contavam com profissionais não qualificados para o exercício da docência.

Quanto à formação docente, cerca de $18 \%$ dos professores declararam nível superior em diversas áreas; $63 \%$ em nível médio com habilitações em magistério e em outros cursos; $11 \%$ apresentaram-se com curso ginasial; e $8 \%$ haviam cursado somente o ensino primário. Com relação à formação específica para lecionar nas séries primárias, $67 \%$ tinham habilitação para a docência deste nível de ensino; 14\% possuíam outras habilitações; e $19 \%$ apresentavam somente os cursos primário e ginasial ${ }^{17}$. Por outro lado, muitos profissionais formados, deixavam de lecionar em escolas rurais, preferindo as escolas urbanas, caracterizando a rotatividade de professores no setor educacional do município.

\section{Considerações finais}

$\mathrm{O}$ artigo procurou abordar aspectos relacionados aos espaços escolares rurais de Cianorte e a organização do ensino nestas instituições. Assim, constitui-se um recorte da pesquisa sobre a história do ensino primário rural neste município, entre as décadas de 1950 e 1990.

Os espaços escolares rurais em estudo, assim como em muitos municípios do Paraná e estados do Brasil, configuraram uma forma de universalizar o ensino primário com baixo custo. A iniciativa de construção destas escolas passou primeiro pela questão da necessidade de atender à população nos locais em que ela se encontrava em maior número, em um período de intenso povoamento e ocupação territorial.

$\mathrm{Na}$ zona rural de Cianorte, a utilização de materiais da própria região para a construção de escolas, com estruturas simples e poucas dependências evidenciam o modelo mais barato e funcional, com a finalidade de democratizar o acesso à educação sistematizada. Há que se considerar que a questão da demanda, o número de salas de aula e a disponibilidade dos professores foram fatores decisivos para a organização do ensino primário nestas escolas. O desdobramento em turnos e as classes multisseriadas e unidocentes refletem os meios possíveis de disponibilizar o ingresso ao ensino a um número maior de crianças e adultos.

Mesmo diante da escassez de materiais e das dificuldades relacionadas à precariedade de recursos, estas instituições encontraram caminhos para a oferta do ensino primário à população do campo. Entre eles, as ações da Associação de Pais e Mestres e a 
atenção periódica dispensada à caixa escolar auxiliaram tanto os alunos carentes como as instituições quanto à sua manutenção.

Nestes espaços e condições as escolas rurais conseguiram ampliar o número de vagas. Mas o desdobramento em turnos por vezes significou o aumento da carga horária de seus professores, muitos sem intervalos entre eles. Grande parte desses profissionais encontrava-se apta a lecionar nas séries primárias, porém a ausência de habilitação específica e de formação mínima marcaram esta realidade.

Tendo em vista o recorte apresentado, esperamos contribuir com o campo da História e Historiografia da Educação. Concluímos que a pesquisa sobre o ensino primário rural numa perspectiva regional esclarece dados sobre o processo educacional e pode suscitar novos debates e investigações no âmbito da história da educação comparada, especialmente sobre a escola primária no meio rural paranaense.

\section{Referências}

ANDRADE, F. A. Escola como agência de civilização: projetos formativos e práticas pedagógicas para a educação rural no Brasil (1946-1964). In: SOUZA, R. F. de; ÁVILA, V. P. da S. de (Orgs.). Dossiê: representações, práticas e políticas de escolarização da infância na zona rural. Hist. Educ. [on line]. Porto Alegre, v. 18, n. 43, p. 93-108, maio/ago. 2014. Disponível em: <http://seer.ufrgs.br/index.php/asphe/article/view/39682/pdf_23> Acesso em: 03 jul. 2015.

ARAÚJO, J. C.; SOUZA, R. F. de; NUNES PINTO, R. M. (Orgs.). Escola Primária na primeira república (1889-1930): subsídios para uma história comparada. Araraquara-SP: Junqueira e Marin Editores, 2012.

ÁVILA, V. P. da S. de. História do ensino primário rural em São Paulo e Santa Catarina (1921-1952): uma abordagem comparada. Araraquara, SP: Unesp, 2013. Tese (Doutorado em Educação) - Universidade Estadual Paulista Júlio de Mesquita Filho, Júlio Mesquita, SP, 2013.

BAREIRO, E. Políticas educacionais e escolas rurais no Paraná - 1930-2005. Dissertação (Mestrado em Educação para a Ciência e o Ensino de Matemática) Universidade Estadual de Maringá, Maringá-PR, 2007.

BRASIL. Lei de Diretrizes e Bases da Educação Nacional n. ${ }^{\circ}$ 4024, de 20 de dezembro de 1961. 1961. Disponível em:

<http://www.planalto.gov.br/ccivil_03/leis/14024.htm>. Acesso em: 17 jul. 2014.

CAINELLI, M. R. Entre a roça e o ditado: a Campanha Nacional de Educação Rural Londrina 1952/1963. Dissertação (Mestrado em História) - Programa de Pós-Graduação em História, Universidade Federal do Paraná, Curitiba, 1994.

CAPELO, M. R. C. Educação, escola e diversidade cultural no meio rural de Londrina: quando o presente reconta o passado. Tese (Doutorado em Educação, Sociedade e Cultura) - Universidade Estadual de Campinas, Campinas, SP, 2000. 
CARDOSO, M. A. A organização do trabalho didático nas escolas isoladas paulistas: 1893 a 1932. Campinas, SP: UNICAMP, 2013. (Tese de Doutorado em Educação) Universidade Estadual de Campinas, Campinas, SP, 2013.

CASTRO, C. A. (Org.). Cultura material escolar: a escola e seus artefatos (MA, SP, PR, SC e RS, 1870-1925). São Luís: EDUFMA, Café \& Lápis, 2011.

CHARTIER, R. A história cultural: entre práticas e representações. Tradução Maria Manuela Galhardo. Rio de Janeiro: Bertrand Brasil, 1990.

CIANORTE. Circular no 03/75 - IRE, de 28 de fevereiro de 1975. Prefeitura Municipal: Divisão de Documentação Escolar, 1975.

Livros Ata de Exames das Escolas Rurais. Prefeitura Municipal: Divisão de Documentação Escolar, 1962-1979.

Livros Ata de Reuniões. Prefeitura Municipal: Divisão de Documentação Escolar, 1970-1989. 1996.

Livros Registro. Prefeitura Municipal: Divisão de Documentação Escolar, 1977-

Projeto de Ampliação da Escola Municipal Rural Tiradentes. Prefeitura Municipal: Divisão de Documentação Escolar, 1997.

- Relatório/Ficha das Escolas Rurais. Prefeitura Municipal: Divisão de Documentação Escolar, s/d.

Relatório/Ficha das Escolas Rurais. Prefeitura Municipal: Divisão de Documentação Escolar, 1971-1972. 1978-1999.

Relatórios Finais. Prefeitura Municipal: Divisão de Documentação Escolar,

CIOFFI, H. et al. Cianorte - sua História contada pelos pioneiros. Maringá, PR: Gráfica Ideal, 1995.

COMPANHIA MELHORAMENTOS NORTE DO PARANÁ (CMNP). Colonização e desenvolvimento do norte do Paraná. Publicação comemorativa do cinquentenário da Companhia Melhoramentos Norte do Paraná. São Paulo: EDANEE, 1975.

DAMASCENO, M. N.; BESERRA, B. Estudos sobre educação rural no Brasil: estado da arte e perspectivas. Educação e Pesquisa, v. 30, n. 1, p. 73-89, jan./abr. 2004.

FARIA FILHO, L. M.; VIDAL, D. G. Os tempos e os espaços escolares no processo de institucionalização da escola primária no Brasil. Revista Brasileira de Educação, n. 14. maio/jun./jul./ago. 2000. Disponível em:

<http://www.scielo.br/pdf/rbedu/n14/n14a03.pdf $>$. Acesso em: 17 jul. 2014. 
INSTITUTO BRASILEIRO DE GEOGRAFIA E ESTATÍSTICA - IBGE. Censo demográfico - Paraná - 1960. Disponível em:

<http://biblioteca.ibge.gov.br/visualizacao/periodicos/68/cd_1960_v1_t14_pr.pdf >. Acesso em: 15 dez. 2014.

Censo demográfico - Paraná - 1970. Disponível em:

$<$ http://biblioteca.ibge.gov.br/visualizacao/periodicos/311/cd_1970_sinopse_preliminar_pr. pdf>. Acesso em: 15 dez. 2014.

Censo demográfico - Paraná - 1980. Disponível em:

<http://biblioteca.ibge.gov.br/visualizacao/periodicos/310/cd_1980_v1_t1_n19_pr.pdf>. Acesso: em 15 dez. 2014.

Censo demográfico - Paraná - 1991. Disponível em:

$<$ http://biblioteca.ibge.gov.br/visualizacao/monografias/GEBIS\%20-\%20RJ/CD1991/CD_ 1991_sinopse_preliminar_PR.pdf>. Acesso em: 15 dez. 2014.

Censo demográfico - 2000. Disponível em:

<http://www.ibge.gov.br/home/estatistica/populacao/sinopse_preliminar/Censo2000sinops e.pdf>. Acesso em: 15 dez. 2014.

JULIA, D. A cultura escolar como objeto histórico. Revista Brasileira de História da Educação. n. 1. jan./jun. 2001. Disponível em:

<http://www.rbhe.sbhe.org.br/index.php/rbhe/article/view/273/281>. Acesso em: 27 fev. 2015

KOHLHEPP, G. Colonização agrária no norte do Paraná: processos geoeconômicos e sociogeográficos de desenvolvimento de uma zona pioneira subtropical do Brasil sob a influência da plantação de café. Maringá, PR: EDUEM, 2014.

LIMA, R. de. História do ensino primário rural em Cianorte-PR (1950-1990). Dissertação (Mestrado em Educação) - Universidade Estadual de Maringá. Maringá, PR, 2015.

LUCHESE, T. Â. Modos de fazer história da educação: pensando a operação historiográfica em temas regionais. In: SOUZA, R. F. de; ÁVILA, V. P. da S. de (Orgs.). Dossiê: representações, práticas e políticas de escolarização da infância na zona rural. Hist. Educ. [on line], Porto Alegre, v. 18, n. 43, p. 145-161, maio/ago. 2014. Disponível em: <http://seer.ufrgs.br/index.php/asphe/article/view/43796/pdf_27> Acesso em: 03 jul. 2015.

MAGAlHÃES, J. P. Tecendo nexos: história das instituições educativas. Bragança Paulista, SP: Editora Universitária São Francisco, 2004.

MIGUEL, M. E. B.; VIDAL, D.; ARAÚJO, J. C. S. (Orgs.). Reformas educacionais: as manifestações da escola nova no Brasil (1920 a 1946). Campinas, SP: Autores Associados; Uberlândia, MG: EDUFU, 2011.

MOTA, L. T.; NOELLI, F. S. Exploração e guerra de conquista dos territórios indígenas nos vales dos Rios Tibagi, Ivaí e Piquiri. In: DIAS, R. B.; GONÇALVES, J. H. R. (Orgs.). 
Maringá e o norte do Paraná: estudos de história regional. Maringá, PR: EDUEM, 1999. p. 21-50.

NOELLI, F. S.; MOTA, L. T. A pré-história da região onde se encontra Maringá, Paraná. In: DIAS, R. B.; GONÇALVES, J. H. R. (Orgs.). Maringá e o norte do Paraná: estudos de história regional. Maringá, PR: EDUEM, 1999. p. 5-19.

PARANÁ. Mensagem apresentada à Assembleia Legislativa do Estado por ocasião da abertura da Sessão Legislativa Ordinária de 1956, pelo Senhor Moysés Lupion, Governador do Paraná. Curitiba-PR, 1956.

Secretaria de Educação e Cultura. O ensino primário no Paraná: nova seriação e programas para as escolas isoladas. Decreto $\mathrm{n}^{\circ} 10.290$, de 13 de dezembro de 1962; Portaria $n^{\circ}$ 110/63. Curitiba: SEEC, 1963a.

Secretaria de Educação e Cultura. O ensino primário no Paraná: nova seriação e programas para os grupos e casas escolares. Decreto $\mathrm{n}^{\circ} 10.290$, de 13 de dezembro de 1962; Portaria n ${ }^{\circ}$ 109/63. Curitiba: SEEC, 1963 b.

Secretaria de Educação e Cultura. Programa Educacional de Emergência. Curitiba: SEEC, 1962.

Secretaria de Estado da Educação. Currículo Básico para a Escola Pública do Estado do Paraná. Curitiba: SEED, 1990. Disponível em: <http://www.grugratulinofreitas.seed.pr.gov.br/redeescola/escolas/21/970/26/arquivos/File/ materialdidatico/diversos/Ensino-Curriculo-Basico-para-a-Escola-Publica-do-Estado-doParana.pdf>. Acesso em: 15 jul. 2014.

PARRA, S. O processo de conversão da ideia de projeto político pedagógico em política educacional pública no Estado do Paraná (1983-2002). Dissertação (Mestrado em Educação) - Universidade Federal do Paraná, Curitiba, 2008.

PINESSO, M. R. F.; MORI, N. N. R. O ciclo básico no Estado do Paraná: a organização do tempo no processo de alfabetização. In: SIMPÓSIO NACIONAL DE EDUCAÇÃO, 1. e SEMANA DE PEDAGOGIA, 20. 11, 12 e 13 de novembro de 2008. Cascavel-PR: Unioeste. 2008. Disponível em:

<http://www.unioeste.br/cursos/cascavel/pedagogia/eventos/2008/5/Artigo\%2001.pdf〉.

Acesso em: 26 jun. 2014.

RAMOS, L. M. P. de C. Escolas rurais consolidadas: a experiência paranaense. Cad. Pesq., São Paulo, p. 19-23, maio, 1991.

RODRIGUES, E. A (re) invenção da educação no Paraná: apropriações do discurso democrático (1980 - 1990). Paraná: EDUEM, 2012.

SCHELBAUER, A. R. Da roça para a escola: institucionalização e expansão das escolas primárias rurais no Paraná (1930-1960). In: SOUZA, R. F. de; ÁVILA, V. P. da S. de (Orgs.). Dossiê: representações, práticas e políticas de escolarização da infância na zona rural. Hist. Educ. [on line]. Porto Alegre, v. 18, n. 43, p. 71-91, maio/ago. 2014. 
Disponível em: <http://seer.ufrgs.br/index.php/asphe/article/view/39687/pdf_22> Acesso em: 03 jul. 2015.

SOUZA, N. L. de. Parque Municipal Cinturão Verde de Cianorte - módulo Mandhuy e sua relação com a cidade de Cianorte, Paraná. Dissertação (Mestrado em Geografia) Universidade Estadual de Maringá, Maringá, PR, 2010.

SOUZA, R. F. de. Alicerces da pátria: história da escola primária no Estado de São Paulo (1890-1976). Campinas, SP: Mercado das Letras, 2009.

Objetos de ensino: a renovação pedagógica e material da escola primária no Brasil, no século XX. In: Dossiê Cultura Material Escolar: abordagens históricas. Educar em Revista, Curitiba: UFPR, n. 49, p. 103-120, jul./set. 2013.

SOUZA, R. F. de; ÁVILA, V. P. da S. de (Orgs.). Dossiê: representações, práticas e políticas de escolarização da infância na zona rural. Hist. Educ. [on line]. Porto Alegre, v. 18, n. 43, maio/ago. 2014. Disponível em:

<http://seer.ufrgs.br/index.php/asphe/issue/view/2276/showToc> Acesso em: 03 jul. 2015.

STECA, L. C.; FlORES, M. D. História do Paraná: do século XVI à década de 1950. Londrina, PR: Ed. UEL, 2002.

TIBUCHESKI, J. K. Educação rural no município de Araucária/PR: de escolas isoladas a escolas consolidadas. Dissertação (Mestrado em Educação) - Universidade Tuiuti do Paraná, Curitiba, 2011.

TOMAZI, N. D. Construções e silêncios sobre a (re)ocupação da região norte do Estado do Paraná. In: DIAS, R. B.; GONÇALVES, J. H. R. (Orgs.). Maringá e o norte do Paraná: estudos de história regional. Maringá, PR: EDUEM, 1999. p. 51-85.

VIDAL, D. G. (Org.). Grupos escolares: cultura escolar primária e escolarização da infância no Brasil (1893-1971). Campinas, SP: Mercado das Letras, 2006.

WERLE, F. O. C. (Org.). Educação rural em perspectiva internacional: instituições, práticas e formação do professor. Ijuí, RS: Ed. UNIJUÍ, 2007.

\footnotetext{
${ }^{1}$ Mestre em Educação pela Universidade Estadual de Maringá. Pedagoga na Rede Estadual de Ensino SEED-PR.

${ }^{2}$ Pós-doutora em História da Educação pela Universidade Federal de Uberlândia. Professora Associada do Departamento de Teoria e Prática da Educação e do Programa de Pós-Graduação em Educação da Universidade Estadual de Maringá.

${ }^{3}$ A nucleação "[...] consiste no agrupamento de pequenas escolas unidocentes de uma região rural em uma Escola-Núcleo, com características próprias de organização e funcionamento, a ideia é proporcionar um ensino de qualidade com instalações e materiais didáticos concentrados em uma única sede escolar" (BAREIRO, 2007, p. 58).

${ }^{4}$ Ver Kohlhepp (2014), Mota e Noelli (1999), Noelli e Mota (1999), Steca e Flores (2002), Tomazi (1999) dentre outros.

${ }^{5}$ No período mencionado, temos “[...] os governos de Manoel Ribas, como interventor (1932-1935 e 19371945) e governador (1935-1937), Moysés Lupion (1947-1951 e 1956-1961) e Bento Munhoz da Rocha Neto (1951-1955) como governadores" (SCHELBAUER, 2014, p. 77).
} 


\footnotetext{
${ }^{6}$ A colonização-dirigida refere-se a um processo de colonização realizado " [...] por empresas ou pelo poder público, cujo planejamento atende à vinda de colonos e onde as terras são divididas e organizados eficientes meios de comunicação e transporte, pois seu objetivo é a venda de terras e o povoamento" (STECA; FLORES, 2002, p. 138).

${ }^{7}$ Os mictórios, utilizados por professores e alunos para as suas necessidades fisiológicas, eram casinhas feitas de madeira, construídas diretamente em cima da fossa sanitária, afastadas da sala de aula por causa dos fortes odores.

${ }^{8}$ Trata-se da Escola Rural Municipal Princesa Isabel (CIANORTE, 1971-1972; s/d).

${ }^{9}$ Trata-se dos seguintes documentos: $O$ ensino primário no Paraná: nova seriação e programas para as escolas isoladas e $O$ ensino primário no Paraná: nova seriação e programas para os grupos e casas escolares (PARANÁ, 1963a e 1963b respectivamente).

${ }^{10}$ Horários de início e término das aulas: $6: 30$ às $10 \mathrm{~h} ; 6: 30$ às $10: 30 \mathrm{~h} ; 6: 40$ às 10:40h; 7 às $10 \mathrm{~h} ; 7$ às 10:30h; 7 às $11 \mathrm{~h} ; 7: 30$ às $10: 30 \mathrm{~h} ; 7: 30$ às $11 \mathrm{~h} ; 8$ às $12 \mathrm{~h} ; 8: 30$ às $12: 30 \mathrm{~h} ; 9$ às $13 \mathrm{~h} ; 9: 30$ às $13: 30 \mathrm{~h} ; 10$ às $13 \mathrm{~h} ; 10$ às $14 \mathrm{~h} ; 10: 30$ às $13: 30 \mathrm{~h} ; 10: 30$ às $14: 30 \mathrm{~h} ; 11$ às $14 \mathrm{~h} ; 11$ às $15 \mathrm{~h} ; 11: 15$ às $17: 15 \mathrm{~h} ; 11: 30$ às $15: 30 \mathrm{~h} ; 12$ às $16 \mathrm{~h}$; $12: 30$ às $15: 30 \mathrm{~h} ; 12: 30$ às $16: 30 \mathrm{~h} ; 12: 30$ às $17: 30 \mathrm{~h} ; 12: 40$ às $16: 40 \mathrm{~h} ; 13$ às $16: 30 \mathrm{~h} ; 13$ às $17 \mathrm{~h} ; 13$ às $17: 30 \mathrm{~h}$; 13:30 às 17:30h; 14 às 17:15h; 14 às $18 \mathrm{~h} ; 15: 30$ às 17:30h; 19 às $22 \mathrm{~h}$ (CIANORTE, 1977-1996).

${ }^{11}$ Exceto referente aos anos de 1993, 1994 e 1997.

${ }_{12}$ Segundo informações contidas nos Relatórios Finais, os conteúdos referentes ao Artigo $7^{\circ}$ seriam trabalhados nas disciplinas: Comunicação e Expressão: Educação Física e Educação Artística; Estudos Sociais: Educação Moral e Cívica e Ensino Religioso; Ciências: Programa de Saúde (CIANORTE, 19781999).

${ }^{13}$ Embora constem as disciplinas de Ed. Física e Ed. Artística nos documentos, não há registros nestes campos.

${ }^{14}$ Embora constem as disciplinas de Ed. Física e Ed. Artística nos documentos, não há registros nestes campos.

${ }^{15}$ Os Livros Registro de 1995 e 1996 não especificam a disciplina, apresentando somente registros de conteúdo. Não há livros referentes ao ano de 1997.

16 “Através do Decreto n. 2545/1988 do Governo do Estado do Paraná, foi instituído o CBA [Ciclo Básico de Alfabetização] nas escolas de $1^{\circ}$ grau da Rede Estadual de Ensino, garantindo ao aluno o prolongamento do tempo de alfabetização inicial de 1(um) para 2 (dois) anos. A regulamentação se deu pela Deliberação n. 28/88 do Conselho Estadual de Educação do Estado do Paraná" (PINESSO; MORI, 2008, p. 02).

17 Os percentuais foram mensurados mediante documentação denominada "cadastro funcional". Os documentos podem ser considerados uma amostragem dos profissionais que atuaram no setor de educação do município entre os anos que recortam a pesquisa. Foram analisados 240 cadastros funcionais.
}

Recebido: $\quad$ março-15 Aprovado: abril-15 